Heredity (1976), 36 (3), 343-350

\title{
A DEMOGRAPHIC ANALYSIS OF THE COMPONENTS OF SELECTION IN A POPULATION OF ARCTIC SKUAS
}

\author{
P. O'DONALD and J. W. F. DAVIS \\ Department of Genetics, University of Cambridge, Milton Road, \\ Cambridge CB4 I XH, England
}

Received 24.x.75

\begin{abstract}
SUMMARY
From previously published demographic data of the age distributions and reproductive rates of the pale, intermediate and dark phenotypes of the Arctic Skua, revised estimates are obtained of the intrinsic rates of increase and selective coefficients of the phenotypes in each sex. Two significant components of selection are variation in age of maturity and variation in reproductive success. Sexual selection is a component of the variation in reproductive success. Dark and intermediate birds have a greater reproductive success than pales, partly as a result of their advantage in sexual selection. Pale birds have an overall advantage, however, because they are younger when they first breed. Given the estimated selective coefficients, a computer model predicts that pale birds will gradually replace the others. So far there are not enough data collected over a sufficiently long time to test the model rigorously.
\end{abstract}

\section{Introduction}

Cavally-Sforza and Bodmer (1971) showed that selective coefficients can be estimated from values of the intrinsic rates of increase of phenotypes in a polymorphism. The Arctic Skua is a polymorphic seabird with pale, intermediate and dark phenotypes in its populations. Arctic Skuas have been studied intensively for many years on Fair Isle, in the Shetlands. O'Donald and Davis (1975) analysed data on the survival and reproductive success of the three phenotypes: their intrinsic rates of increase and selective coefficients were then calculated by Cavalli-Sforza and Bodmer's formulae.

The survivorship of Arctic Skuas has only been observed for adult birds, starting from the year when they first bred in the population. The adult birds are ringed with colour-coded rings, so that their survival can be observed from one year to the next. Doubtful birds, who have lost some of their rings, can easily be caught again and their rings replaced. However, the survival of the newly fledged chicks up to the age when they return to breed can only be estimated from the overall survival rates and the ages of chicks breeding for the first time. In the past, not many chicks, still with their original rings, have been recovered as breeding adults. During the last three years, however, we have been using very durable monel rings on the chicks, and thus hope to recapture all those who return to breed. This should produce direct observations on their chances of survival. O'Donald and Davis (1975) found that pale birds matured earlier than the others: on average they were about 0.6 of a year younger when they first bred in the population. They therefore have a considerable selective advantage because they have a greater chance of surviving to breeding age. This difference in 
the mean age of maturity is very significant statistically, although it is based on a total of only 52 chicks. More data are necessary in order to obtain accurate estimates of the effect of this component of selection.

Sexual selection is also a component of the overall selection of the phenotypes (O’Donald, Wedd and Davis, 1974; O'Donald and Davis, 1975). The dark and intermediate males appear to be more successful in finding a new mate: they mate earlier in the breeding season than the pale males, gaining a selective advantage as a result of the greater reproductive success of earlier breeding pairs; their improved chances of mating may be caused by female mating preferences (O'Donald, Wedd and Davis, 1974; O'Donald, 1976). The consequent variation in reproductive success among the male phenotypes is a component of highly significant variation in reproductive success among the phenotypes of both sexes.

Variation in survival, reproductive success and age of maturity may all contribute to the overall selection of the phenotypes. As estimates of the intrinsic rates of increase and selective coefficients, Cavalli-Sforza and Bodmer's formulae are first approximations; when applied to the data of the Arctic Skua, they underestimate the selective coefficients. In a note added to their paper in proof, O'Donald and Davis (1975) gave more accurate estimates of the overall intrinsic rates of increase and selective coefficients, based on a further and more exact analysis of the data. We present here the details of this analysis: we analyse the selection into its components and estimate the corresponding intrinsic rates of increase and selective coefficients; we also calculate the evolutionary consequences of the selection. The data, on which our present calculations are based, have already been published in tables 1, 2 and 3 of the previous paper (O'Donald and Davis, 1975).

\section{Estimation OF INTRINSIC RATES OF INGREASE AND SELEGTIVE GOEFFIGIENTS}

Lotka's equation for a population with a stable age distribution is

$$
\sum_{x} e^{-r x} l_{x} b_{x}=1
$$

where $r$ is the intrinsic rate of increase, $l_{x}$ the proportion of individuals that survive to age $x$, and $b_{x}$ the average number of offspring produced at that age. Cavalli-Sforza and Bodmer (1971) assume that $r x$ is small, and as a first approximation put $e^{-r x}=1-r x$ giving the solution

where

$$
r=\left(R_{0}-1\right) / R_{1}
$$

$$
R_{0}=\sum_{x} l_{x} b_{x} \text { and } R_{1}=\sum_{x} x l_{x} b_{x}
$$

This formula is not sufficiently accurate when applied to the data of the Arctic Skua: the average intrinsic rate of increase is underestimated by about 30 per cent. However, $r$ can be estimated to any required degree of accuracy using a series in powers of $r$ of which the coefficients are calculated from the statistics

$$
R_{j}=\sum_{x} x^{j} l_{x} b_{x} \quad(j=0,1,2, \ldots)
$$


The series is given by the equation

where

$$
\log _{e} R_{0}=\alpha r+\beta r^{2} / 2+\gamma r^{3} / 3+\delta r^{4} / 4+\ldots,
$$

$$
\begin{aligned}
& \alpha=R_{1} / R_{0} \\
& \beta=\alpha^{2}-R_{2} / R_{0} \\
& \gamma=\alpha^{3}-\frac{3}{2} R_{2} R_{1} / R_{0}^{2}+\frac{1}{2} R_{3} / R_{0} \\
& \delta=\alpha^{4}-2 R_{2} R_{1}^{2} / R_{0}^{3}+\frac{2}{3} R_{3} R_{1} / R_{0}^{2}+\frac{1}{2} R_{2}^{2} / R_{0}^{2}-\frac{1}{6} R_{4} / R_{0} .
\end{aligned}
$$

The analytical basis of these calculations was originally given by Dublin and Lotka (1925). Pielou (1969) gives a recently published account. If a second-order approximation is to be used we have the equation

giving the estimate

$$
\log _{e} R_{0}=\alpha r+\beta r^{2} / 2
$$

$$
r=\frac{-1+\sqrt{1+2\left(1-R_{2} R_{0} / R_{1}^{2}\right) \log _{e} R_{0}}}{R_{1} / R_{0}-R_{2} / R_{1}}
$$

The generation time, $T$, can then be found from the formula

$$
T=\alpha+\beta r / 2+\gamma r^{2} / 3+\delta r^{3} / 4+\ldots
$$

The statistics, $R_{0}, R_{1}, \ldots, R_{j}, \ldots$, cannot be calculated directly for the Arctic Skua, because the ages of the birds are known, not from the year they fledged, but from the year they first returned to breed. Only when they are incubating eggs is it possible to catch and ring them. If $x^{\prime}$ is the number of years an adult bird has bred in the population and $l^{\prime}$ its probability of surviving for those years, then

$$
\begin{aligned}
& l_{x}=l_{m} l^{\prime} \\
& x=m+x^{\prime},
\end{aligned}
$$

where $m$ is the number of years before breeding and $l_{m}$ the probability of surviving from fledging to breeding age. Since we have

then by putting

$$
R_{j}=\Sigma\left(m+x^{\prime}\right)^{j} l_{m} l^{\prime} b
$$

we get the equations

$$
R_{j}^{\prime}=\Sigma\left(x^{\prime}\right)^{j} l^{\prime} b
$$

$$
\begin{aligned}
& R_{0}=l_{m} R_{0}^{\prime} \\
& R_{1}=l_{m} R_{1}^{\prime}+m R_{0} \\
& R_{2}=l_{m} R_{2}^{\prime}+2 m R_{1}-m^{2} R_{0} \\
& R_{3}=l_{m} R_{3}^{\prime}+3 m R_{2}-3 m^{2} R_{1}+m^{3} R_{0} \\
& R_{4}=l_{m} R_{4}^{\prime}+4 m R_{3}-6 m^{2} R_{2}+4 m^{3} R_{1}-m^{4} R_{0} .
\end{aligned}
$$

The values of $m$ and $l_{m}$ for the different phases are given in table 3 of O'Donald and Davis (1975). The values of $l^{\prime}$ are obtained from tables 1 and 2. They 
are average values for birds maturing with a probability of $l_{m}$ at an average age of $m$.

Given values of $r$ for the three phenotypes, the relative fitnesses and selective coefficients can then be calculated as suggested by Cavalli-Sforza and Bodmer (1971). If $r_{1}$ is the intrinsic rate of increase of one phenotype and $r_{2}$ that of another, then the relative fitness of the two phenotypes can be measured by the ratio

$$
w=e^{r_{1} T} / e^{r_{2} T}=e^{\left(r_{1}-r_{2}\right) T},
$$

where $\bar{T}$ is the mean generation time. We have taken $\bar{T}$ from the formula for $T$ using the mean intrinsic rate of increase of the females. The mean rates differ between males and females as a result of a few very long-lived females in the population of Arctic Skuas on Fair Isle. The values of $w$ are not much affected by small differences in $\bar{T}$, however; and the use of $\bar{T}$ for females gives values of $w$ and the selective coefficients, $s=1-w$, that are consistent between the sexes when the same selection acts on them both.

Since the intermediates, as we classify them in our present research, are nearly all heterozygotes, while the darks and pales are homozygotes, the estimated fitnesses and selective coefficients relate directly to genotypes in a genetic polymorphism. Thus predictions can be made of changes in gene frequency in subsequent generations. O'Donald and Davis (1975) found that the allele for pale would eventually replace the allele for dark. The present analysis confirms this conclusion.

\section{Results}

The distributions given in O'Donald and Davis' table 1 (1975) have been used to calculate the values of $R_{j}(j=1,2,3,4)$ and hence the intrinsic rates of increase of the three phenotypes of the Arctic Skua. These estimates include the effects of variation in survival, reproductive success and age of maturity. Table 1 of this paper shows the results of these calculations.

The selective coefficients shown in table 1 represent very large selective differences between the phenotypes. The factors of survival, reproductive success and age of maturity, which contribute to these differences, can be analysed by calculating the values of $r$ produced by variation in each factor separately. Thus, in the calculations of $r$, one factor may be allowed to vary among the phenotypes while the other factors are averaged for all phenotypes. O'Donald and Davis (1975) estimated the variation in intrinsic rate of increase that would be caused solely by the variation in the age of maturity. The values of $R_{0}$ and $r$ were calculated from the values of $m$ and $l_{m}$ for each phenotype and the numbers of chicks fledged by birds of each age regardless of phenotype.

The selective effects of survival and reproductive success can also be analysed separately in a similar way. We can find, for each phenotype and for all phenotypes, the average number of chicks fledged by birds of each age. Thus we can find the numbers of chicks fledged when the age distribution of the birds is averaged over all phenotypes and when their fledging success is averaged over all phenotypes. When these calculations are carried out, the high values of $R_{0}$ for pale birds can clearly be seen to depend on the few, very long-lived pale birds. An analysis of variance shows that the average ages of the breeding adults do not differ significantly between the phenotypes. Yet 
TABLE 1

Calculation of intrinsic rates of increase and selective coefficients determined by variation in survival, reproductive success and age of maturity

\begin{tabular}{|c|c|c|c|c|}
\hline $\begin{array}{c}\text { Phase and } \\
\text { sex }\end{array}$ & $\begin{array}{c}\text { Reproductive } \\
\text { rate } \\
R_{0}\end{array}$ & $\begin{array}{c}\text { Intrinsic rate } \\
\text { of increase } \\
r\end{array}$ & $\begin{array}{c}\text { Relative } \\
\text { fitness } \\
w\end{array}$ & $\begin{array}{c}\text { Selective } \\
\text { coefficient } \\
s\end{array}$ \\
\hline Pale males & $1 \cdot 580$ & 0.0514 & $0 \cdot 877$ & $0 \cdot 123$ \\
\hline Intermediate males & $1 \cdot 300$ & $0 \cdot 0305$ & $0 \cdot 727$ & $0 \cdot 273$ \\
\hline Dark males & $1 \cdot 691$ & $0 \cdot 0660$ & $1 \cdot 000$ & $0 \cdot 0$ \\
\hline All males & $1 \cdot 471$ & 0.0461 & 一 & - \\
\hline Pale females & $2 \cdot 132$ & $0 \cdot 0858$ & $1 \cdot 000$ & $0 \cdot 0$ \\
\hline Intermediate females & $1 \cdot 728$ & $0 \cdot 0582$ & $0 \cdot 780$ & $0 \cdot 220$ \\
\hline Dark females & $1 \cdot 201$ & 0.0242 & 0.575 & 0.425 \\
\hline All females & $1 \cdot 723$ & 0.0605 & - & - \\
\hline
\end{tabular}

The values of $r$ represent the 4th order approximations, calculated from the power series up to the 4th power of $r$. The second approximation is very close indeed, but slightly overestimates the values of $r$ in the 4th significant digit. The selective coefficients have been calculated using the mean generation time $T=8.997$ for females. These estimated selective coefficients differ slightly from those given in the note added in proof to O'Donald and Davis' paper (1975). There, the mean generation time was calculated from the actual intrinsic rate of increase between the year 1962 and 1973. This is not, however, typical of the overall rate of increase because the islanders illegally shot many birds between those years. For consistency in estimating the selective coefficients, we have used the estimated value of $r$ in calculating $T$. There are also slight differences in the values of $R_{0}$ for intermediates and darks compared with those given in the previous paper. In this paper we have used values of $m$ and $l_{m}$ calculated separately for intermediates and darks: in the previous paper, the average values were used for both these phenotypes.

the differences in survival cause most of the differences in the selective coefficients. The variation in survival would by itself give rise to the following selective coefficients:

$\begin{array}{lccc} & \text { Pale } & \text { Intermediate } & \text { Dark } \\ \text { Males } & 0.099 & 0 \cdot 179 & 0 \\ \text { Females } & 0 & 0 \cdot 169 & 0.393\end{array}$

These selective coefficients, large as they are, are not significantly different. Therefore, no inferences can be drawn from them about survival as a selective factor in Arctic Skua populations.

Age of maturity and reproductive success both vary significantly between the phenotypes (O'Donald, Wedd and Davis, 1974; O'Donald and Davis, 1975). We now analyse the selective effects of these two factors separately and together. Tables 2, 3 and 4 give the values of $R_{0}, r, w$ and $s$ that are obtained if age of maturity, reproductive success, or both factors together, vary between the phenotypes. Sexual selection is a component of the variation between males in reproductive success, and favours the dark and intermediate males. O'Donald, Wedd and Davis (1974) found that the selective coefficient of sexual selection measuring the relative disadvantage of pale males was approximately $s=0 \cdot 070$. This is about half the selective disadvantage of pale males that is caused by their lower reproductive success. Pale birds of both sexes have an overall advantage, however, because of their earlier average age of maturity. 
TABLE 2

Component of selection resulting from variation in age of maturity

\begin{tabular}{lcccc}
\multicolumn{1}{c}{$\begin{array}{c}\text { Phase and } \\
\text { sex }\end{array}$} & $\begin{array}{c}\text { Reproductive } \\
\text { rate } \\
R_{0}\end{array}$ & $\begin{array}{c}\text { Intrinsic rate } \\
\text { of increase }\end{array}$ & $\begin{array}{c}\text { Relative } \\
\text { fitness }\end{array}$ & $\begin{array}{c}\text { Selective } \\
\text { coefficient }\end{array}$ \\
Pale males & 1.635 & $0 \cdot 0627$ & $w$ & $s$ \\
Intermediate males & $1 \cdot 407$ & $0 \cdot 0398$ & $1 \cdot 000$ & $0 \cdot 0$ \\
Dark males & $1 \cdot 418$ & $0 \cdot 0408$ & $0 \cdot 815$ & $0 \cdot 185$ \\
Pale females & 1.916 & $0 \cdot 0771$ & $1 \cdot 000$ & $0 \cdot 179$ \\
Intermediate females & $1 \cdot 649$ & $0 \cdot 0543$ & $0 \cdot 815$ & $0 \cdot 0$ \\
Dark females & $1 \cdot 661$ & $0 \cdot 0552$ & $0 \cdot 821$ & $0 \cdot 185$ \\
& & &
\end{tabular}

The values of $r$ in this table are considerably larger than the corresponding values for this component of selection given in O'Donald and Davis (1975). As in table 1, the values of $R_{0}$ for darks and intermediates differ slightly from those given in the previous paper in which values of $m$ and $l_{m}$ were averaged over darks and intermediates. There is no difference between the sexes in age of maturity. The selection acting on the phenotypes is thus the same in males and females.

\section{TABle 3}

Component of selection resulting from variation in reproductive success

\begin{tabular}{|c|c|c|c|c|}
\hline $\begin{array}{l}\text { Phase and } \\
\text { sex }\end{array}$ & $\begin{array}{c}\text { Reproductive } \\
\text { rate } \\
R_{0}\end{array}$ & $\begin{array}{c}\text { Intrinsic rate } \\
\text { of increase } \\
r\end{array}$ & $\begin{array}{c}\text { Relative } \\
\text { fitness } \\
w\end{array}$ & $\begin{array}{c}\text { Selective } \\
\text { coefficient } \\
s\end{array}$ \\
\hline $\begin{array}{l}\text { Pale males } \\
\text { Intermediate males } \\
\text { Dark males }\end{array}$ & $\begin{array}{l}1 \cdot 363 \\
1 \cdot 438 \\
1 \cdot 584\end{array}$ & $\begin{array}{l}0 \cdot 0365 \\
0 \cdot 0430 \\
0 \cdot 0563\end{array}$ & $\begin{array}{l}0 \cdot 837 \\
0 \cdot 887 \\
1 \cdot 000\end{array}$ & $\begin{array}{l}0 \cdot 163 \\
0 \cdot 113 \\
0 \cdot 0\end{array}$ \\
\hline $\begin{array}{l}\text { Pale females } \\
\text { Intermediate females } \\
\text { Dark males }\end{array}$ & $\begin{array}{l}1 \cdot 571 \\
1 \cdot 764 \\
1 \cdot 754\end{array}$ & $\begin{array}{l}0 \cdot 0501 \\
0 \cdot 0636 \\
0 \cdot 0634\end{array}$ & $\begin{array}{l}0 \cdot 885 \\
1 \cdot 000 \\
0 \cdot 998\end{array}$ & $\begin{array}{l}0 \cdot 115 \\
0 \cdot 0 \\
0 \cdot 002\end{array}$ \\
\hline
\end{tabular}

TABLE 4

Component of selection resulting from variation in both age of maturity and reproductive success

\begin{tabular}{lcccc}
\multicolumn{1}{c}{$\begin{array}{c}\text { Phase and } \\
\text { sex }\end{array}$} & $\begin{array}{c}\text { Reproductive } \\
\text { rate }\end{array}$ & $\begin{array}{c}\text { Intrinsic rate } \\
\text { of increase }\end{array}$ & $\begin{array}{c}\text { Relative } \\
\text { fitness }\end{array}$ & $\begin{array}{c}\text { Selective } \\
\text { coefficient }\end{array}$ \\
Pale males & 1.515 & $r$ & $w$ & $s$ \\
Intermediate males & 1.376 & 0.0522 & 1.000 & 0.0 \\
Dark males & 1.527 & 0.0369 & 0.871 & 0.129 \\
Pale females & 1.746 & 0.0507 & 0.986 & 0.014 \\
Intermediate females & 1.688 & 0.0658 & 1.000 & 0.0 \\
Dark females & 1.690 & 0.0573 & 0.926 & 0.074 \\
& & 0.0580 & 0.932 & 0.068
\end{tabular}

When selection is calculated from intrinsic rates of increase, fitnesses of each component of selection are neither exactly additive nor exactly multiplicative: fitness is a complicated function of the statistics $R_{j}(j=1,2, \ldots)$. Significant components of fitness are variation in age of maturity and variation in reproductive success. The fitnesses determined by these components 
can be combined additively or multiplicatively. The resulting fitnesses and selective coefficients are compared in table 5 with the values obtained when both age of maturity and reproductive success vary simultaneously (table 4). Additive combination of fitnesses considerably underestimates the true values and multiplicative combination slightly overestimates them.

\section{TABLE 5}

Comparison of the results of combining fitnesses additively and multiplicatively for the components of age of maturity and reproductive success

\begin{tabular}{|c|c|c|c|c|c|c|}
\hline \multirow[b]{3}{*}{$\begin{array}{l}\text { Phase and } \\
\text { sex }\end{array}$} & \multicolumn{4}{|c|}{ Method of combining fitnesses } & \multirow{2}{*}{\multicolumn{2}{|c|}{$\begin{array}{c}\text { Simultaneous } \\
\text { estimation } \\
\text { (table } 4)\end{array}$}} \\
\hline & \multicolumn{2}{|c|}{ Additive } & \multicolumn{2}{|c|}{ Multiplicative } & & \\
\hline & $w$ & $s$ & $w$ & $s$ & $w$ & $s$ \\
\hline Pale males & $1 \cdot 000$ & 0 & $1 \cdot 000$ & 0 & $1 \cdot 000$ & 0 \\
\hline Intermediate males & $0 \cdot 875$ & $0 \cdot 125$ & $0 \cdot 864$ & $0 \cdot 136$ & 0.871 & $0 \cdot 129$ \\
\hline Dark males & $1 \cdot 016$ & $-0 \cdot 016$ & 0.981 & 0.019 & 0.986 & $0 \cdot 014$ \\
\hline Pale females & $1 \cdot 000$ & 0 & $1 \cdot 000$ & 0 & $1 \cdot 000$ & 0 \\
\hline Intermediate females & 0.944 & $0 \cdot 056$ & 0.920 & $0 \cdot 080$ & 0.926 & $0 \cdot 074$ \\
\hline Dark females & 0.949 & 0.051 & 0.926 & 0.074 & 0.932 & $0 \cdot 068$ \\
\hline
\end{tabular}

The multiplicative combination of fitnesses gives values fairly close to those obtained by simultaneous estimation.

In 1962 the gene frequency of the dark allele was 0.5582 in males and 0.4753 in females (O'Donald and Davis, 1975). Using the fitnesses given in table 4 , the subsequent changes in gene frequency can be predicted. These are given in table 6 , showing that the allele for dark should eventually be

TABLE 6

Predicted gene frequencies in successive generations

\begin{tabular}{ccr} 
& \multicolumn{2}{c}{$\begin{array}{c}\text { Gene frequency of allele } \\
\text { for dark }\end{array}$} \\
\cline { 2 - 3 } In females & In males \\
1 & 0.5081 & $0 \cdot 5160$ \\
2 & $0 \cdot 5031$ & $0 \cdot 5109$ \\
3 & 0.4980 & $0 \cdot 5056$ \\
4 & 0.4927 & $0 \cdot 5001$ \\
5 & 0.4872 & $0 \cdot 4943$ \\
10 & 0.4557 & $0 \cdot 4614$ \\
20 & 0.3719 & $0 \cdot 3738$ \\
30 & $0 \cdot 2616$ & $0 \cdot 2594$ \\
40 & $0 \cdot 1481$ & $0 \cdot 1441$ \\
50 & $0 \cdot 0668$ & $0 \cdot 0639$ \\
100 & 0.0004 & 0.0004
\end{tabular}

eliminated from the populations of the Arctic Skua. The results are qualitatively similar to those given by O'Donald and Davis (1975), but the rate of selection is reduced because the non-significant component of variation in survival has been eliminated. After one generation of selection, the observed gene frequency was in fact 0.5143 when averaged in males and females. The 
predicted frequency is 0.5120 giving a very close fit to the observed value $\left(\chi^{2}=0.0085\right)$. This test of fit is based on a sample of only 210 birds. Changes in gene frequency would not be detectable over several generations at the rate predicted by the model given the fitnesses determined by age of maturity and reproductive success.

\section{REFERENCES}

CAVAlli-Sforza, L. L., AND bodmer, w. F. 1971. The Genetics of Human Populations. W. H. Freeman and Co., San Francisco.

DUBlin, L. I., AND LOTKA, A. J. 1925 . On the true rate of natural increase. F. Amer. Stat. Ass., 20, 305-339.

o'DONALD, P. 1976. Mating preferences and their genetic effects in models of sexual selection for colour phases of the Arctic Skua. Population Genetics and Ecology, ed. Karlin, S., and Nevo, E. Academic Press, New York.

o'DONALD, P., AND DAvis, J. W. F. 1975. Demography and selection in a population of Arctic Skuas. Heredity, 35, 75-83.

o'DONALD, P., WEDD, N. S., AND DAvis, J. W. F. 1974. Mating preferences and sexual selection in the Arctic Skua. Heredity, 33, 1-16.

PIElou, E. C. 1969. An Introduction to Mathematical Ecology. John Wiley and Sons, New York. 